\title{
LA CONSTITUCIÓN NARRATIVA DE LA IDENTIDAD Y LA EXPERIENCIA DEL TIEMPO
}

\author{
Carlos de Castro \\ Universidad de Murcia
}

Resumen.- Este artículo parte de la idea de que la identidad está ligada a la experiencia del tiempo. Las recientes transformaciones sociales han alterado la experiencia temporal de numerosos colectivos, cuyas narraciones previas ya no les permiten ordenar sus agitadas experiencias temporales. Este artículo explora la idea de que las identidades son el resultado de establecer una conexión entre los diferentes aspectos temporales de la experiencia y de que esa conexión constituye el "trabajo identitario", el cual consiste, principalmente, en la configuración de una narración. En consecuencia, la identidad depende del modo en que cada narración combine los múltiples aspectos temporales de las diferentes esferas sociales por las que transcurre la vida de cada persona (coherencia) y de la forma en que se establezca una conexión entre el pasado, el presente y el futuro (continuidad). Inspirado en las aportaciones de White (1992) y Gergen (1996), este artículo concluye distinguiendo cuatro tipos de narraciones según el tipo de trama (novela, comedia, tragedia, sátira), tramas que constituyen formas distintas de conjugar temporalmente los acontecimientos.

Palabras clave.- identidad, tiempo, narración, reflexividad

Abstract.- This article begins with the idea that identity is linked to the experience of time. Recent social changes have altered the temporal experience of many groups, whose previous narratives were no longer possible to organize their complicated temporal experiences. This article explores the idea that identities are the result of a connection between the different temporal aspects of the experience and that this connection constitutes the "identity work", which mainly consists in the shaping a narrative. Consequently, the identity depends on how each narrative combine multiple temporal aspects of the different social areas which integrate the life of each person (consistency) and how to establish a connection between past, present and future (continuity). Inspired by the contributions of White (1992) and Gergen (1996), this paper concludes by distinguishing four types of narratives (romance, comedy, tragedy, satire), which combine the different temporal aspects of several events.

Key words.- identity, time, narrative, reflexivity

\section{Introducción ${ }^{1}$}

La reciente reorganización temporal de las empresas y de los mercados de trabajo ha provocado una profunda alteración de la experiencia temporal de los trabajadores (Sennett, 2000). El futuro asegurado de las contrataciones indefinidas ha sido sustituido por un futuro más precario propio de la contratación temporal. La experiencia acumulada en el pasado nunca parece suficiente como para alcanzar o consolidarse en un empleo. El presente, por su parte, se ha convertido en una amalgama de horarios y plazos desacoplados. En consecuencia, la experiencia temporal propia de los trabajadores tiene que ver con la incertidumbre con respecto a un futuro cada vez más corto, con el desapego con respecto al pasado, con la eterna sensación de no tener tiempo

\footnotetext{
${ }^{1}$ Una primera versión de este artículo se presentó como comunicación en el X Congreso Español de Sociología celebrado en Navarra en julio de 2010.
} 
para nada (escasez), de no llegar a tiempo (agobio), de ir siempre corriendo (prisa), etc... Aunque crecientemente extendida, no se trata una experiencia del tiempo compartida por todos los trabajadores. Al contrario, las experiencias temporales son plurales en la medida en que los tiempos también lo son.

Este artículo parte de la idea de que la identidad está ligada a la experiencia o a la vivencia del tiempo. En consecuencia, la diversidad de la experiencia temporal puede conducir a formas específicas de concebir, de representar y de utilizar el tiempo vivido y puede dar lugar a una determinada estructura temporal de la identidad. La estructura temporal que adquiera la identidad va a depender de la forma en que se combinen los múltiples aspectos temporales de las diferentes esferas sociales por las que transcurre la vida de cada persona (coherencia) y de la forma en que se establezca una conexión entre el pasado, el presente y el futuro (continuidad).

Las diferentes posturas dentro del debate sobre las identidades comparten una serie de presupuestos acerca de la coherencia y de la continuidad temporal. Por un lado, comparten la idea de que la experiencia temporal de los individuos se encuentra atravesada por una ruptura con respecto al pasado y por el acortamiento y la incertidumbre del futuro, lo cual dificulta el establecimiento de una continuidad temporal en la experiencia. Por otro lado, comparten la idea de la fragmentación de los marcos temporales de la experiencia, cuya coordinación era la garantía para el establecimiento de la coherencia temporal.

Los defensores de una identidad reflexiva (Giddens, 1995; Beck y BeckGernsheim, 2003), a pesar de que reconocen las dificultades, afirman que la continuidad y la coherencia de la identidad del sujeto son posibles gracias al esfuerzo reflexivo del individuo en la construcción de su propia identidad. Por su parte, los que afirman que las identidades son fragmentadas (Bauman, 2003, 2006; Sennett, 2000), sostienen que la discontinuidad entre el pasado y el futuro y la fragmentación de los órdenes temporales de la experiencia son insalvables y que, en consecuencia, los sujetos se ven abocados a vivir siempre desgarrados y a la deriva, con un escaso margen de control sobre sí mismos y sobre su destino. Por último, radicalizando la postura previa, los posmodernos (Lyotard, 1989; Baudrillard, 1978, 1998) afirman que el futuro y el pasado han colapsado en el presente de manera que pasado, presente y futuro son ahora simultáneos. En consecuencia, el sujeto se dispersa caóticamente por la diversidad de instantes efímeros que integran su experiencia, de manera que la reunión de semejante diversidad en un orden temporal continuo y coherente resulta una tarea imposible.

Por otra parte, el problema de las anteriores posturas sobre la identidad radica en que o bien presuponen que los individuos se encuentran permanentemente inmersos y vinculados en sus redes sociales y culturales sin que exista la posibilidad de distanciarse de ellas, o bien dan por supuesto que se encuentran completamente desvinculados o distanciados de ellas ${ }^{2}$, dando, además, por

2 Se trata de algo que ocurre tanto en la versión moderna liberal representada por Giddens como en la versión postmoderna radical representada por Lyotard. Giddens concibe el proceso de desvinculación y revinculación como un proceso automático y siempre dirigido autónoma y conscientemente por el sujeto, mientras que Lyotard entiende que el sujeto se ha desintegrado al deshacerse los lazos sociales que le conformaban. 
supuesto que la posterior re-vinculación a los nuevos contextos se realiza de una manera completamente aproblemática ${ }^{3}$.

Para superar estas limitaciones, proponemos analizar el proceso de configuración de la identidad con el fin de explorar una doble idea. Por un lado, se plantea que la identidad es el resultado de un proceso de distanciamiento reflexivo iniciado por el sujeto con respecto a su contexto social originario. Un distanciamiento que crea un nuevo orden temporal interior en el que se coordinan los diversos aspectos temporales de la experiencia. Por otro lado, se plantea que la coordinación de los aspectos temporales de la identidad se realiza por medio de la configuración de una narración y que por tanto las identidades son identidades narrativas. El objetivo de este artículo consiste en mostrar que las identidades se crean en un tercer tiempo que no es el tiempo exterior ni el tiempo interior sino el tiempo de la narración de ahí que las identidades sean identidades narrativas.

Este artículo se divide en dos partes. En la primera parte se analiza el proceso de distanciamiento y su relación con la identidad, mientras que en la segunda parte se analiza el papel de las narraciones en articulación de la diversidad de la experiencia temporal y en la configuración de la identidad.

\section{Distanciamiento, tiempo e identidad}

Sostenemos que un análisis del proceso de configuración de la identidad debe partir del estudio del proceso de distanciamiento del contexto. El proceso de distanciamiento del contexto va a ser un elemento constitutivo de la identidad ${ }^{4}$ en la medida en que crea una nueva dimensión temporal de la experiencia ${ }^{5}$ y permite que se desarrolle la propia reflexividad del sujeto.

El proceso de distanciamiento se puede dividir en dos partes que son las dos caras del mismo proceso. Primero, la propia acción del distanciamiento y, segundo, aquello con respecto a lo que uno se distancia: el contexto de origen. Con respecto a la primera parte, Wagner señala que el distanciamiento del contexto es uno de los principales rasgos de la modernidad (2001: 84). En primer lugar, porque el distanciamiento del contexto suele acarrear un terremoto espiritual de intensidad variable cuyo resultado puede ser la reflexividad o la toma de conciencia de uno mismo como semejante a unos y diferente a otros. El descubrimiento reflexivo de la individualidad que nos

3 Para Wagner aquí se encuentra el meollo de la modernidad. Wagner describe la modernidad como la generalización del exilio (2001). La cuestión es cómo aprender a vivir con los demás, cómo aprender a vivir con aquellos que no se encuentran en los círculos de las relaciones originarias. Todo aprendizaje requiere un distanciamiento de los círculos previos y todo distanciamiento significa en alguna medida aprender a dejar algo atrás, a perder (Philibert). La nostalgia supone la expresión de las dificultades en el aprendizaje de la pérdida. Por otra parte, toda desvinculación supone iniciar un proceso de distanciamiento con respecto a las relaciones originarias. Se trata de un proceso que puede dar lugar a una sensación de pérdida, puesto que hay algo que se deja atrás, un pasado irrecuperable, o puede dar lugar a una sensación de desorientación, puesto que uno no sabe lo que le espera ni lo que se encontrará en adelante, un futuro incierto.

4 Sobre la idea de distanciamiento del contexto, véase Wagner (2001, cap 4)

5 Un tercer tiempo que no es ni el tiempo externo del mundo ni el tiempo de la conciencia (Ricoeur, 1995). O en palabras de Luhmann, "una extensión no temporal de tiempo" (Luhmann, 1992). 
singulariza va acompañado, sin embargo, del descubrimiento de su carácter contingente, histórico y, por tanto, prescindible y frágil. Uno podría haber sido otro e, incluso, podría no haber sido.

En segundo lugar, el distanciamiento del contexto permite relativizar las categorías sociales por medio de las que definimos nuestra relación con el mundo, con los grupos y con nosotros mismos. Éstas pierden su aparente carácter prefijado, esencial e inalterable y empieza a hacerse visible su carácter contingente, histórico, constructivo. Por tanto, se trata también del descubrimiento de que las formas de identificación varían históricamente y de que varían entre diferentes grupos sociales.

En tercer lugar, el distanciamiento representa también el descubrimiento de la alteridad. Distanciarse de uno mismo implica encontrarse con los otros y sus respectivas temporalidades ya sea para su afirmación o para su negación. Se descubre, por tanto, que cada grupo posee formas específicas de identificación que se encuentran en interacción con las de los otros aunque las fronteras entre ellas no sean muy claras. Se descubre igualmente que las formas de identificación de unos grupos predominan sobre otros en razón de sus relaciones de dominación. Aprender a convivir con los demás supone, pues, aprender a ampliar el conjunto de referencias temporales que pueden ser constitutivas de la identidad del sujeto. A lo largo del proceso de distanciamiento, surgen, además, nuevas formas de identificación que articulan la doble operación de diferenciación y de igualación que constituyen las identidades. El distanciamiento implica así el inicio de una etapa de permanente creación de diferencias más o menos estables, siempre renovables y siempre provisionales según la transformación de los grupos y de la realidad social.

Con respecto al contexto del que uno se distancia, esta forma de dar cuenta de la acción de distanciarse no debería reducir el contexto a una realidad completamente preexistente y objetiva. Al contrario, en el ámbito de la reflexión sobre la identidad, los rasgos del contexto se delimitan simultáneamente con los de la identidad, son constitutivos de la identidad. Esto no implica negar la existencia real y objetiva del contexto sino más bien acentuar la relación que establece el sujeto con su contexto concreto de relaciones sociales con sus específicas temporalidades. Un contexto del que el sujeto no puede tomar conciencia en su totalidad sino que opera sobre él una selección. Así pues, al iniciar el distanciamiento, el sujeto aprende a identificar las temporalidades específicas de cada contexto y a combinarlas según sus necesidades.

Pero, ¿por qué dar por supuesto que el proceso de distanciamiento del contexto tiene lugar en todos los individuos del mismo modo? ¿Por qué presuponer que todos los individuos rompen sus lazos con el pasado (o son expulsados de él) e intentan domesticar un futuro incierto? El hecho de que ocurra o no, de que predomine en unos y no en otros segmentos sociales o el hecho de que ocurra de un determinado modo en cada lugar ayuda a comprender la ambivalencia de los rasgos de la identidad (Wagner, 2001). Así, en primer lugar, uno de los supuestos más extendidos es que la identidad ha pasado de ser un destino a ser una elección. Sin embargo, que sea una u otra cosa puede depender de que el individuo se haya distanciado de su contexto y haya empezado a percibir que aquellas categorías antes tan familiares podrían 
ser rechazadas para elegir otras. E incluso podría darse el caso de que se distanciara de una parte del amplio contexto y no de otra y así, por ejemplo, podría cuestionar la categoría de obrero pero no hacer lo propio con la categoría de género, o viceversa. En consecuencia, algunos rasgos podrían ser el resultado de una elección deliberada mientras que otros podrían presentarse como un destino inescrutable y natural.

En segundo lugar, otro de los supuestos más extendidos es que la identidad pasa de ser una realidad objetiva a ser una construcción social. Sin embargo, no todos los rasgos identitarios son el resultado de una construcción consciente y racional, más bien sólo aquellos rasgos "originales" con respecto a los que previamente se ha producido algún tipo de distanciamiento. De manera que puede ocurrir que las identidades puedan estar compuestas de rasgos naturalizados, en el sentido de que nunca han sido puestos en cuestión, rasgos que aparecen indiferenciados de uno mismo como si fueran realidades objetivas, como una segunda piel; y de rasgos construidos, en el sentido de que uno ha redefinido las categorías familiares $o$ ha tenido acceso a un repertorio de nuevas categorías cognitivas y perceptivas con las que ha podido modificar su relación con el mundo, con los demás y consigo mismo.

Un tercer supuesto ampliamente compartido es que las construcciones identitarias han pasado de ser colectivas a ser individuales en un doble sentido. Primero, la identidad se presenta como el resultado de una construcción totalmente individual y, segundo, es que estas identidades son completamente distintas las unas de las otras, no parece haber nada común o semejante. Cada individuo parece ser una mónada completamente original. Así por un lado, la participación de los otros (familiares, escuelas, instituciones políticas, organizaciones) en la configuración de uno mismo ha tendido a ser interpretada o bien como una imposición o bien como una dominación. En consecuencia, se ha enfatizado en la autonomía o falta de autonomía del individuo para configurarse a sí mismo. Una vez más, ambas pueden coexistir. La percepción de la autonomía sólo es posible tras haber iniciado el distanciamiento del contexto originario de socialización, pero como el distanciamiento no se produce del contexto en su conjunto sino tan sólo de algunas parcelas, puede ocurrir que uno se considere cómo autónomo en unas parcelas de la existencia mientras que en otras se considere como completamente dependiente 0 dominado. La participación de los otros en la configuración de la identidad no ocurre necesariamente en relaciones asimétricas sino que también puede tener lugar en relaciones horizontales y entabladas voluntariamente. Por otro lado, las identidades deben comprenderse como un continuo proceso de igualación y de diferenciación. Se trata más bien una mezcla de elementos compartidos que reciben su originalidad del modo en los sujetos se apropian de ellos en cada momento y en cada contexto.

En resumen, las identidades siempre son construidas pero nunca lo son completamente. Son el resultado de procesos de construcción siempre inacabados, siempre en curso, y siempre en diálogo y en tensión con la otra parte aún "inocente" o "natural" o "espontánea" de lo que somos. Esta tensión es la que refleja Ricouer (1995) con la oposición entre la mismidad y la ipseidad, una tensión que, como veremos, sólo se resuelve narrativamente y dará lugar a "un vástago inesperado": la identidad del sujeto. Además, por ser una construcción, las identidades son siempre una búsqueda deliberada, pero 
nunca escapan completamente de un "destino" personal, social, político o cultural. Como Bauman (2003) venía a decir, la construcción de la identidad implica la búsqueda de un lugar y de un sentido en un mundo sin las certezas originarias. $\mathrm{Y}$, por último, las identidades son construidas por uno mismo y por los otros. El descubrimiento del otro es también ambivalente. El otro puede ser yugo o liberación. Sin embargo, enfrentarse a la dominación no supone desterrar el decisivo papel de los otros en la constitución de uno mismo.

Quedaba por analizar la nueva dimensión temporal de la existencia que abría el distanciamiento ${ }^{6}$. El proceso de distanciamiento supone el establecimiento de una ruptura con respecto al pasado como consecuencia de vislumbrar un futuro diferente. En palabras de Koseleck (1993), este abismo entre la experiencia del pasado y el horizonte del futuro representa la orientación temporal típicamente moderna, la manera moderna de relacionarse con el pasado y con el futuro. El tiempo, por tanto, deja de ser un flujo continuo y ordenado de acontecimientos, en el sentido de que el futuro no era más que la repetición del pasado. La ruptura de la continuidad entre el pasado y el futuro obliga a la búsqueda de nuevas formas de coordinación entre ambos. Para el individuo supone el inicio de la búsqueda de nuevas forma de establecer una continuidad entre ambos planos temporales para así dotar de coherencia a su experiencia.

Pero, tras el distanciamiento, la relación entre el pasado y el futuro ha cambiado. Antes del distanciamiento, el pasado guiaba "pre-conscientemente" los pasos del futuro. Pasado, presente y futuro permanecían iguales los unos a los otros. Tras el distanciamiento, el pasado y el futuro van a ser siempre diferentes entre sí. Por lo tanto, el distanciamiento del contexto implica una permanente diferenciación temporal. Luhmann (1992) consigue captar esa nueva relación con el pasado y el futuro en su concepto de tiempo. Para Luhmann el tiempo es una interpretación de la realidad con respecto a la diferencia entre el pasado y el futuro (1992: 166). Desde este punto de vista, el sujeto no experimenta el tiempo como una línea continua sino cómo algo que está partido justo en el punto dónde él se yergue (Arendt, 2003: 26). La propia diferenciación entre el pasado y el futuro, el establecimiento de esa brecha o de esa distancia, es constitutiva del sujeto. Llegar a ser alguien implica, pues, establecer una distinción entre el pasado y el futuro que nunca es definitiva

6 La distinción entre lo comunitario y lo societario hace referencia a una distinción temporal. Se puede decir que "lo comunitario" es un territorio imaginario, es el resultado de la construcción de un pasado desde el presente en el que se ha producido o se está produciendo el distanciamiento de lo "originario", de aquello que hasta entonces se daba por supuesto y no se había cuestionado. Se trata de un pasado que sólo es posible descubrir o construir en el después del distanciamiento. Según Pardo (2004), una anterioridad posterior. Antes de la separación del contexto, habíamos aprendido a ser de una determinada manera, a observar el mundo, a relacionarnos con uno mismo y con los otros, pero sin saber que hacíamos todo eso ni cómo. Un proceso de aprendizaje no consciente que Bourdieu ha recogido bajo el concepto de habitus. Esa "inconsciencia" remite a un estado de inocencia, a la espontaneidad o a la naturalidad de lo que fue aprendido sin querer, sin darnos cuenta. Era un tiempo, el momento anterior al distanciamiento, en el que todo se presentaba como una unidad sin fisuras, como una realidad objetiva, inapelable, incontestable. Pero no es algo que pertenezca al pasado de las sociedades sino al pasado de las biografías individuales y colectivas. La nueva dimensión temporal abierta por el distanciamiento sería "una extensión no temporal de tiempo" (Luhmann, 1992). El distanciamiento sería, por tanto, la ruptura o la puesta entre paréntesis de un proceso de socialización, aculturación, identificación que empezó mucho antes de que nos diéramos cuenta. 
puesto que pasado y futuro son horizontes del presente, y como tales siempre inalcanzables7. De esta manera el sujeto vive siempre a caballo entre un futuro que no puede empezar y un pasado que no puede terminar. Así pues, sostenemos que la permanente diferenciación entre pasado y futuro así como el esfuerzo por mantener algún tipo de continuidad entre ambos representan dos elementos constitutivos de la identidad del sujeto.

La experiencia temporal de los individuos marcada por una permanente diferenciación entre el pasado y el futuro pone de manifiesto que tanto el mundo como las identidades cambian permanentemente. Ante esta permanente experiencia del cambio, el problema consiste en cómo mantener una identidad reconocible y estable. La solución a este problema es temporal en la medida que se trata de integrar la experiencia del cambio en la temporalidad de la estructura de la identidad. Así pues, uno de los rasgos más importantes de la estructura temporal de la identidad es la predisposición al cambio. Por tanto, la identidad no es tan sólo algo que se llega a ser sino que también es ese proceso por el que uno llega a ser ese algo. Sin embargo esto no debería llevarnos a afirmar que el proceso identitario (el devenir) sustituye a la realidad de la identidad (del ser), sino más bien a afirmar que el proceso (el devenir) es constitutivo de la identidad (del ser) ${ }^{8}$ (Wagner, 2001; Hall, 2005; Pardo, 2004).

Si esto es así el proceso de configuración de la identidad representaría una de las manifestaciones del irresoluble conflicto entre el tiempo del mundo y el tiempo de la conciencia (Ricouer, 1995). Este énfasis en lo procesual nos permitiría escapar de nociones esencialistas, por las que la identidad aparece como una sustancia compacta y predefinida que se expande a lo largo del tiempo, y de aquellas nociones constructivistas que desconocen cualquier tipo de límite y contexto la configuración de una identidad, cuya unificación no es más que una pretensión ingenua. Ricouer va a proponer una solución narrativa que medie entre las dos dimensiones temporales de la experiencia que son irreductibles entre sí. En otras palabras, la discordancia temporal del mundo se puede solucionar provisional y pragmáticamente a través de la creación de una concordancia narrativa (Ricoeur, 1995). La discordancia temporal de la experiencia tiene lugar a dos niveles. Primero, el tiempo exterior (el mundo en cambio) no siempre transcurre al ritmo del tiempo de la conciencia ni siempre es controlable por esta. Y segundo, el pasar del tiempo no siempre se percibe de la misma manera. El pasado, el presente y el futuro están en permanente redefinición. La diferencia entre el pasado y el futuro se modifica de acuerdo con los cambios del presente. En otras palabras, tanto el pasado como el futuro son horizontes del presente (Luhmann, 1992). La discordancia temporal es tan ineliminable como los esfuerzos colectivos e individuales por establecer un ordenamiento temporal de la experiencia por medio de la configuración de una narración. Así pues, la concordancia no es un atributo del mundo ni de la

7 Por otra parte, de esto se deduce que lo que ocurrió (pasado) y lo que ocurrirá (futuro) no son importantes en sí mismos sino por el modo en que se seleccionan y se conectan entre sí en la narración

8 Wagner (2001) afirma la existencia de un cambio del ser al devenir (becoming). Una propuesta muy ligada a la tradición aristotélica que pensó el ser desgajado en dos partes: el acto y la potencia. El ser se compondría de lo que ya es en acto y del permanente movimiento desde la potencia al acto (Ricoeur, 1996: 335-8; Pardo, 2004). Es decir, uno es lo que es y lo que puede llegar a ser, la distancia entre lo uno y lo otro es también constitutiva del ser. 
experiencia, sino de las narraciones. Si esto es así, las narraciones no informan sobre la realidad sino sobre el sujeto que narra, un sujeto que se constituye al narrar. Lo que sostenemos, por tanto, es que a medida que el sujeto elabora una narración sobre su relación con la realidad social, está constituyendo su identidad, una identidad narrativa.

\section{La estructura temporal de la identidad y las narraciones}

La estructura temporal de la identidad está formada por dos series temporales. La serie A se refiere al pasado, al presente y al futuro mientras que la serie B se refiere a la organización temporal de la vida cotidiana (duraciones, distribuciones, ritmo...)

La serie $A$ se refiere a las formas en que desde el presente nos imaginamos y nos relacionamos con el pasado y el futuro. El concepto moderno de futuro enfatiza la apertura a la novedad y su progresión hacía un estado de perfección. Sin embargo, el futuro abierto es ambivalente. Si bien es cierto que acoge en su seno las mejores de las esperanzas, también encuentra su sitio en él la posibilidad de la catástrofe. Esa es la cara que los teóricos sociales actuales parecen enfatizar, de ahí que, para ellos, el horizonte de futuro sea cada vez más incierto y a corto plazo.

Por otra parte, uno de los aspectos temporales de la identidad se refiere a la forma de imaginar y de relacionarse con el pasado. El concepto moderno del pasado está muy ligado a la idea de la desvinculación de la tradición y, paradójicamente, a la nostalgia de esos lazos tradicionales (Wagner, 2001, 80121). Actualmente se comparte el presupuesto de que la tradición ha desaparecido (destradicionalización) y de que, incluso, también lo ha hecho la nostalgia de una tradición. Mejor que compartir estos presupuestos es atender a la manera de relacionarse con el pasado, de recordar, de hacer memoria, de recuperar la experiencia como elemento necesario para actuar $y$, consecuentemente, la eventual la aparición de la nostalgia, del arrepentimiento, del desapego o rechazo del pasado.

La forma de concebir el futuro y de recuperar el pasado orienta la organización temporal del presente de la vida cotidiana convirtiéndola así en un instrumento para alcanzar los planes trazados. La serie $B$ se refiere a la organización temporal de la vida cotidiana y de la biografía y se refiere a la duración de cada etapa de la vida o de cada actividad que uno realiza cada día o cada semana, se refiere al momento del día o de la semana en que uno ubica aquellas actividades que desea realizar y a la etapa de la vida en que uno ubica algún proyecto orientándose por el momento propicio según el ritmo de la vida de cada uno o de la organización en la que se encuentra, se refiere a la regularidad con que ocurren algunos acontecimientos en la vida personal durante diversos periodos de tiempo, a la secuencia que describen,...

Nosotros sostenemos que la estructura temporal de la identidad, que es el resultado del distanciamiento del contexto, se crea por medio de la configuración de una narración. Además, se trata de una estructura discursiva que va a adquirir diferentes formas según el tipo de trama.

El esfuerzo de los sujetos por conjugar y ordenar los múltiples y heterogéneos aspectos temporales que conforman su experiencia puede denominarse como 
"trabajo identitatio" (Revilla, 2009; Padavic, 2005; Westenholz, 2006). En este contexto analítico, las aportaciones de Ricoeur $(1995,1996)$ adquieren una relevancia decisiva. Siguiendo la estela de Ricoeur, en este capítulo se sostiene que el trabajo identitario individual es principal, pero no exclusivamente, un "trabajo narrativo". Dicho de otra forma, los individuos ordenan los diferentes aspectos temporales de su experiencia por medio de la configuración de una narración. Se trata de una estructura narrativa que crea un nuevo orden temporal, un "tercer tiempo" (1995: 996), el tiempo narrado, que no niega ninguna de las dimensiones temporales de la experiencia del sujeto sino que las integra en su interior. Pero el desarrollo de la narración trae consigo algo más. Al contar una historia que pretende unificar los múltiples retazos que conforman la vida de una persona, no se presupone la existencia previa de la identidad de un sujeto que narra, sino que es la propia narración la que va forjando tanto al sujeto como a su identidad. En consecuencia, el sujeto de las acciones es el personaje de la historia que cuenta sobre su vida y la identidad del personaje es la identidad narrativa (1995 vol III: 997; 1996: 142147).

La propuesta de Ricouer constituye, pues, una vía reflexiva hacia la identidad, es decir, una hermenéutica del sí. La hermenéutica, según Ricoeur, parte de considerar que la comprensión de sí es una interpretación de lo que uno hace y dice que encuentra en la narración una mediación privilegiada (1996: 107, nota 1). La identidad narrativa se refiere, por tanto, a la interpretación que uno realiza de sus acciones en la medida en que éstas son una respuesta a la solicitud del otro y al intento de ser fiel a la palabra dada al otro. La interpretación de uno mismo remite a una operación de apropiación de los acontecimientos engarzándolos en un relato coherente.

\section{La identidad narrativa: entre la mismidad del carácter y el mantenimiento del sí}

Para Ricoeur el problema de la identidad personal sólo puede articularse en la dimensión temporal de la existencia humana (1996: 107). Se trata de un problema que pone en cuestión la permanencia de la persona en el tiempo (idem: 109). En sus propias palabras, "¿qué justifica que se tenga al sujeto de la acción...como el mismo a lo largo de una vida que se extiende desde el nacimiento hasta la muerte?" (1995 vol.III: 997, cursiva añadida). Para Ricoeur, como ahora se verá, "la respuesta a esa pregunta sólo puede ser narrativa", es decir, "...consiste en contar la historia de una vida. La historia narrada dice el quién de la acción. Por lo tanto la propia identidad del quién no es más que una identidad narrativa" (1995 vol III: 997, cursiva original).

Según Ricoeur (1995: 997-8), las soluciones ofrecidas al problema de la identidad son insatisfactorias. Unas porque han afirmado exaltadamente la existencia de un sujeto desvinculado, incorpóreo y libre de presupuestos que se mantiene inalterable e idéntico a sí mismo a lo largo del tiempo a pesar de las transformaciones (el devenir) de la realidad que le rodea. Se trata, pues, de una concepción de la identidad que presupone su inmutabilidad y que es completamente impermeable a la integración de los cambios. Otras, por su parte, porque se han esforzado en subrayar que un sujeto así es una mera ilusión para, a continuación, afirmar que la originalidad y la heterogeneidad de 
los sujetos es inconmesurable e irreductible a cualquier concepto de identidad. El sujeto aparece así dispersado entre los múltiples episodios desconectados que integran su vida. Se trata, pues, de una concepción de la identidad incapaz de comprender la permanencia. A partir de esta lectura de las filosofías del sujeto, la cuestión que se plantea Ricoeur es la de articular un concepto de identidad narrativa que pueda incluir "el cambio, la mutabilidad en la cohesión de una vida" (idem: 998).

El problema de las dos posturas mencionadas se encuentra, según Ricoeur, en que comparten una visión sustancialista de la identidad. Ambas reducen la identidad a la mismidad. La propuesta de Ricoeur de una identidad narrativa se basa en la distinción de la identidad como idem o mismidad ${ }^{9}$ y la identidad como ipse o ipseidad $^{10}$. La mismidad se refiere a los rasgos concretos de la identidad (carácter) mientras que la ipseidad se refiere a las acciones (narrativas) del agente encaminadas a mantener la palabra dada al otro (1996: 110-120). En resumen, Ricoeur aborda el problema de la permanencia de la persona en el tiempo estableciendo una oposición entre la mismidad del carácter y el mantenimiento del sí en la promesa. El carácter y la palabra dada van a representar, pues, dos modelos complementarios e irreductibles de permanencia de la persona en el tiempo que proponen dos formas distintas de relacionar la mismidad y la ipseidad (id: 112).

El carácter designa el conjunto de disposiciones y de identificaciones duraderas que han sido adquiridas de forma casi inadvertida, por la silenciosa acción de la costumbre (id.: 113-118). El resultado es que algo que ha sido aprendido y adquirido por el sujeto lentamente a lo largo del tiempo aparece como inmutable, como inalterable, como mismidad. Este es el lado irreflexivo de la identidad, es decir, aquello que se llega a ser sin darse cuenta, rutinariamente. Es un modo de ser espontáneo, natural, no aprendido conscientemente, es el momento previo a la acción del distanciamiento cuando da la impresión de que uno forma una unidad inquebrantable con el mundo. Esta sedimentación del carácter es lo que posibilita que el ipse aparezca como idem, es decir, que sean casi indistinguibles. Sin embargo, se apresura a subrayar Ricoeur, "este recubrimiento [del ipse por el idem] no anula la diferencia de sus problemáticas: incluso como segunda naturaleza, mi carácter soy yo, yo mismo, ipse; pero este ipse se enuncia como idem" (1995: 116). Esta es la forma que tiene Ricoeur de reconocer los límites de la narración (y de la reflexividad) en la constitución de la identidad. Parece querer afirmar que hay una parte no controlable, no narrativizable en lo que somos que a veces puede aparecer bajo la conocida forma del destino. Sin embargo, a pesar de su apariencia inmutable, el carácter tiene una historia de la que la narración del ipse, aunque sea parcialmente, puede llegar a apropiarse a condición de iniciar un distanciamiento reflexivo con respecto a aquello que uno supuestamente es ${ }^{11}$ (1996: 117, 169). La identidad del ipse no es, por tanto, el conjunto de los

9 El idem o la mismidad (lo mismo, sameness) se refiere a la parte sustantiva o material de la identidad: los atributos concretos de una persona. Es la parte no reflexiva de la identidad, lo que nos viene dado.

10 El ipse o la ipseidad (el sí mismo, selfhood) se refiere al agente que se constituye a sí mismo por medio de la configuración de una narración. Es la parte reflexiva de la identidad.

11 Sobre la similitud de este lado no reflexivo de la identidad con el concepto de habitus de Bourdieu, ver Lahire (2004). 
rasgos del carácter sino la apropiación narrativa de tales rasgos (lo dado) que está guiada por el cumplimiento de la palabra dada al otro (lo posible).

La palabra dada representa, por su parte, un modelo de permanencia en el tiempo plenamente reflexivo (id.: 118-120). La relación entre idem e ipse cambia radicalmente, pasan de ser prácticamente coincidentes a estar completamente separados. En términos temporales esto significa que, en el primer caso, la continuidad entre el pasado, el presente y el futuro era inquebrantable y, por tanto, era el pasado el que orientaba la experiencia. En el segundo caso, se produce la escisión entre el pasado y el futuro. El futuro será ahora el que sirva de guía para intentar trazar una frágil continuidad en la experiencia. En este modelo la figura de ipse es predominante y se proyecta hacia el futuro en el acto de la promesa. El esfuerzo por mantener la palabra dada al otro es interpretado por Ricoeur como un intento de mantenerse a uno mismo en la palabra dada, lo cual supone que para poder ser responsable de sus acciones frente al otro uno debe intentar mantenerse inalterable. Aquí entra en juego algo que Giddens denominaba el proyecto del yo (1993). Se pretende llegar a ser voluntaria y reflexivamente un determinado tipo de sujeto que establece un determinado tipo de compromiso con el otro. El modo en que uno se hace cargo de sus acciones y define sus proyectos es por medio de las narraciones. Aquí Ricoeur pretende afirmar la parte controlable de lo que somos, la parte de la que se puede responder frente al otro, lo cual tiene importantes implicaciones éticas ${ }^{12}$. La ipseidad no remite, pues, a algo que se posee sino a la propia acción de la apropiación guiada por el compromiso con el otro. De hecho, la ipseidad requiere un cierto grado de desposeimiento que pueda facilitar la irrupción del otro en el terreno de sí (1996: 171). La ipseidad, según Ricoeur, requiere una dialéctica de la posesión y el desposeimiento. Los casos aportados por las ficciones narrativas sobre la pérdida de la identidad ( $E l$ hombre sin atributos de Musil) representan un caso extremo de desposesión en el que el ipse ha sustituido al idem. El otro caso extremo sería el que representa la filosofía cartesiana del sujeto en el que el idem oscurece por completo la presencia del ipse. Frente a ello, Ricoeur propone la solución dialéctica. El problema, sin embargo, es que ante la actual tendencia hacia la desvinculación, que implica una permanente y acelerada renovación de los rasgos, viene a dificultar el compromiso con los otros, lo que implica que el ipse queda cada vez más en un segundo plano.

El reto que va a asumir Ricoeur va a consistir en la elaboración de un concepto de identidad lo suficientemente flexible para admitir el cambio y para facilitar la participación de los otros. La identidad narrativa se sitúa, por tanto, en el espacio intermedio entre la permanencia del carácter y el mantenimiento de sí en la promesa ${ }^{13}$. Es decir, la configuración de la narración debe mediar entre la mismidad (lo no reflexivo, lo dado) y la ipseidad (lo reflexivo) sin reducir una a la otra. De manera que ahora es necesario comprender cómo se construye la permanencia temporal por medio de una narración, qué tipos de narraciones hay y cómo de ellas surge la identidad del sujeto.

12 Ricoeur explora las cuestiones éticas de la identidad narrativa en los estudios séptimo y octavo de Sí mismo como otro (1996: 173-257).

13 Así pues, "la identidad narrativa oscilará entre dos límites. Un límite inferior, donde la permanencia en el tiempo expresa la confusión entre idem e ipse; y un límite superior, donde ipse plantea la cuestión de su identidad sin la ayuda y el apoyo de idem" (1996: 120) 


\section{Las narraciones y las tramas. Narración, tiempo e identidad}

Ricoeur va a proponer un tercer modelo de permanencia de la persona en el tiempo que se basa en la capacidad configuradora de las narraciones. La estructura de una narración es permeable tanto a los cambios como a las demandas de los otros significativos, lo cual significa admitir que tanto los cambios como los otros son constitutivos de la identidad.

Frente a la celebración o a la denuncia de un devenir episódico e incontrolable de los acontecimientos y frente a la exaltación del control humano de los acontecimientos, Ricoeur muestra que la construcción de una trama representa el modelo de conexión entre acontecimientos más adecuado para integrar en la permanencia en el tiempo la diversidad, la discontinuidad y el cambio (1996: 139). Es decir, la construcción de la trama pretende dotar a la vida de una unidad narrativa que simultáneamente mantenga la tensión entre los elementos que la integran y que sea, al mismo tiempo, el soporte de la identidad. En otras palabras, la trama conjuga una exigencia de concordancia con una admisión de un cierto grado de discordancia que puede desbaratar la identidad. La configuración de una narración consiste, por tanto, en una síntesis de lo heterogéneo, en una concordancia discordante (1995: 141-146; 1996: 139140).

Antes de continuar y dar cuenta del modo en que las narraciones constituyen la identidad y su temporalidad específica, nos vamos a detener a aclarar los conceptos de narración y de trama.

Para Ricouer, la narración es una representación o imitación (mímesis) de la acción por medio de la construcción de una trama (mythos) (Ricouer, 1995: 8291). Hay tres elementos a tener en cuenta: las acciones, la representación y la trama.

Las acciones representadas no se refieren sólo a los hechos, a los acontecimientos sufridos por el sujeto o a las acciones protagonizadas por él sino también a sus fines, a sus motivos, a los agentes que intervienen, a algunas consecuencias de sus acciones, a las circunstancias y al resultado de las acciones (idem: 116-7). Además, Ricouer amplia la noción de la acción para incluir en ella la transformación moral del personaje, su crecimiento, educación y maduración personal, así como su formación afectiva, emocional y sentimental (idem: 388).

Por su parte, la representación y la trama no son estructuras prefijadas sino operaciones creativas. Las representaciones se realizan a través de diversas figuras lingüísticas que dan cuenta de una específica relación con la realidad. La mímesis trasciende la función referencial del lenguaje y, en consecuencia, la relación de correspondencia con la realidad. Basándose en la Poética de Aristóteles, Ricoeur entiende que la mímesis se refiere al proceso activo de imitar o representar, una representación que no puede comprenderse en términos de copia o de réplica en la medida en que la representación produce algo. $Y$ ese algo que produce es, precisamente, el orden que introduce en los hechos, esto es, la disposición de los hechos mediante la trama (idem: 83, 85). En consecuencia, la mimesis recurre a otras figuras lingüísticas, los tropos. Los tropos del lenguaje ponen en suspenso la función referencial del lenguaje, en la 
medida en que se emplean en un sentido distinto al literal. Plantean una relación no de correspondencia con la realidad sino de semejanza y de desemejanza. La metáfora, la metonimia y la sinécdoque establecen una relación de semejanza mientras que la ironía fija una relación de desemejanza ${ }^{14}$. Estas figuras pueden combinarse y adquirir formas específicas en la construcción de la trama. Además, todas ellas pueden utilizarse para dar cuenta del tiempo.

Para Ricouer, la trama, basándose igualmente en Aristóteles, se refiere a la "disposición de los hechos en sistema" (1995: 82). La trama que cumple varias tareas: enlaza los acontecimientos, crea un sentido de unidad entre ellos y remite a una convención narrativa ${ }^{15}$.

El requisito inicial de una trama es el establecimiento de un punto final, de un propósito, de una meta. Uno habla, narra desde ese punto final en relación al cual selecciona, ordena y evalúa los acontecimientos. El final aporta, entonces, el criterio de selección de los acontecimientos relevantes ${ }^{16}$ para la narración y el criterio de ordenación de dichos acontecimientos. Por tanto, los acontecimientos y las acciones no son significativos por sí mismos o aisladamente sino que son significativos tan sólo en la medida en que están conectados con otros acontecimientos dentro de una trama, en la que la sucesión de acontecimientos tiene un principio, un inicio desde el que se dirigen hacia un final (Gergen, 1996: 233; White, 1992: 16). La trama conecta elementos muy heterogéneos (acontecimientos, acciones, fines, motivos, consecuencias esperadas y no esperadas,...) y, al hacerlo, les dota de sentido y les hace seguibles unos a partir de otros. En otras palabras, la narración se hace inteligible en la medida en que los acontecimientos seleccionados y sus conexiones son relevantes con respecto al final.

Una vez fijado el final, la trama incluye acontecimientos y acciones que son relevantes con respecto a ese final y los dispone "en sistema", esto es, configura una sucesión ordenada que crea un sentido de unidad o de totalidad. Por tanto, los diversos acontecimientos y acciones reunidos en la trama se convierten en una narración sólo cuando forman una unidad o una totalidad en la que se puede distinguir un principio, un desarrollo y un final ${ }^{17}$.

La narración no puede, sin embargo, introducir cualquier orden en los hechos sino que está sujeta a límites. Gergen (1996) señala que las configuraciones narrativas no son universales sino que son histórica y culturalmente contingentes y, en consecuencia, pueden variar de un contexto socio-cultural a otro y de una época a otra. Por tanto, los límites de nuestra forma de relacionar los acontecimientos no se encuentran en los propios acontecimientos ni en nuestra mente sino en los tipos de narraciones arquetípicas disponibles en el acervo cultural de los diversos contextos sociales en los que se desarrollan las relaciones sociales ${ }^{18}$. Estas formas narrativas establecen los límites de la comprensión de una narración y, en consecuencia, una narración que no se

14 Para una descripción detallada de cada uno de los tropos del lenguaje, véase White (1992) 15 Ramos (1995: 34) propone que la trama cumple una triple tarea de configuración: engarza, aúna (o totaliza) y alegoriza (o tipifica) el acontencer, haciéndolo así significativo, comprensible y persuasivo. Esta primera operación sería el engarce.

16 Koseleck (1993) y Ricouer (1995)

17 Es lo que Ramos (1995) denomina la tarea de aúnar.

18 Este es el momento en que la trama alegoriza o ejemplifica, según Ramos (1995b) 
aproxime a estas formas narrativas podría no ser reconocida y ser incomprensible o ilegible para la comunidad o el grupo de referencia.

White (1992: 18-21), Ricouer (1995: 397), Gergen (1996: 241) y Ramos (1995, inédito fecha: 10-11) han considerado la propuesta de Northrop Frye (1957) como la más completa y ambiciosa en este sentido. Frye (1957) señala que en las narraciones de la cultura occidental dispersas en la literatura, cuentos, leyendas, mitos,.. se pueden distinguir cuatro tipos básicos de tramas: romance o novela, comedia, tragedia y sátira. Proponemos aclarar esta tipología atendiendo a la relación que la narración establece entre las intenciones y los acontecimientos. En una narración los acontecimientos se seleccionan y se engarzan según el propósito o la meta perseguida. Las metas y los propósitos hacen referencia a las intenciones de las acciones emprendidas por los personajes de la narración. Según Boudon (citado en Ramos, 1993: 448) en las intenciones de la acción pueden distinguirse los aspectos volitivos, que se refieren a lo que uno desea o quiere, y los aspectos cognitivos, que se refieren a lo que uno espera o prevé. Así pues, las intenciones de las acciones incluirían tanto las metas, propósitos o fines como las expectativas. Si ponemos en relación los acontecimientos con los dos aspectos de las intenciones, tendríamos que lo que ocurre puede ser querido y esperado, querido pero no esperado, no querido y no esperado y, por último, no querido aunque esperado. Cada uno de los tipos de trama de Frye respondería claramente a cada una de las opciones señaladas (ver cuadro).

\section{Cuadro. Tipos de trama}

\begin{tabular}{|c|c|c|c|}
\hline & Aspectos & cognitivos de las & intenciones \\
\hline \multirow{2}{*}{$\begin{array}{c}\text { Aspectos volitivos } \\
\text { de las } \\
\text { intenciones }\end{array}$} & Deseable & Previsible & Imprevisible \\
\cline { 2 - 4 } & Indeseable & Tragedia & Comedia \\
\cline { 2 - 4 } & & Sátira \\
\hline
\end{tabular}

En la novela o romance, todo transcurre según lo esperado y lo deseado. El personaje anhela alcanzar la meta hacia la que la dinámica de los acontecimientos parece empujarle. No obstante, en este tipo de trama hay un momento para el drama. A medida que el personaje se aproxima al final, surge la intriga acerca de que algo pueda ocurrir que aparte violentamente al personaje de aquello que quiere y desea. Cuando ese algo ocurre dan comienzo las aventuras del personaje en su lucha contra todos los obstáculos que han salido a su encuentro. El acontecimiento que ha generado la tensión dramática no ha supuesto un cambio en la dirección de la historia sino que ha servido para convertir al personaje en un héroe. Es, por tanto, la historia de la ascensión, de la redención o de la superación personal del personaje (Frye, 1957). En otras palabras, en el romance uno espera y desea que todo salga bien y, al final, a pesar de los obstáculos, todo sale bien. Un final feliz tal y como se esperaba y deseaba. 
En la comedia y en la tragedia los acontecimientos se suceden de forma inesperada $y$, por tanto, se comportan irónicamente con respecto a las voluntades, intenciones y expectativas ${ }^{19}$, aunque de formas distintas. En la comedia, en un principio la acción transcurre de un modo desfavorable, no querido o no deseado para el personaje, sin embargo, llegados a un punto se produce un inesperado giro en los acontecimientos que conduce al personaje hacia sus metas iniciales. Todo concluye, por tanto, en un final feliz pero no debido a las acciones del personaje, como en el romance, sino a una ocasional reconciliación de las "fuerzas oscuras" que dominan la sociedad y la naturaleza (White, 1992: 20). En otras palabras, en la comedia, aunque uno desea que todo salga bien, cree que todo va a salir mal, pero, de repente $\mathrm{e}$ inesperadamente, ocurre algo que conduce los acontecimientos hacia un final feliz, deseado pero inesperado.

Al contrario que en el romance o novela en la que se contaba la historia de la ascensión o de la redención o de la superación del personaje, en la tragedia se cuenta la historia de su caída, de su desgracia, del final de su inocencia. Al principio de la narración, el personaje cree encaminarse hacia el fin que anhela, pero, sin embargo, sucede algo inesperado que trastoca los acontecimientos para oponerlos a sus deseos. La única redención o superación al alcance del personaje de una tragedia es una fugaz revelación de la naturaleza de esas "fuerzas oscuras" que se oponen a su voluntad y que rigen férreamente su destino. Además, el personaje alcanza a comprender que sus propias acciones han alimentado involuntariamente esas fuerzas tan contrarias a sus intenciones, esperanzas y deseos. En resumen, en la trama trágica todo termina inesperadamente de la peor manera posible.

Por último, la sátira es la trama típica del absurdo en la que el personaje, a pesar de que desconoce las "fuerzas" que rigen el mundo y el destino de los hombres, cree que los acontecimientos se comportarán indefectiblemente de manera contraria a sus deseos. La trama satírica representa un mundo cuya dinámica es ilegible, absolutamente carente de sentido e impermeable a las acciones humanas y que, además, arrasa con los proyectos, esperanzas y deseos de los personajes. Por otra parte, el personaje de la sátira no alberga ninguna esperanza de una repentina y afortunada reconciliación de las "fuerzas" que guían los acontecimientos, sino que cree que es un ser arrastrado por "fuerzas" que no puede comprender ni controlar. Por tanto, no hay lugar para historias de superación personal puesto que los personajes se

19 Ramos (inédito: 3-6) destaca la relevancia de la ironía para las ciencias sociales en la medida en que los acontecimientos sociales y políticos están regidos por consecuencias no intencionales de acciones intencionales. En el ámbito de las ciencias sociales, entiende la ironía, junto con Brown, como "una metáfora de los contrarios... [que permite] asignar sentido a las cosas gracias al descubrimiento de relaciones insospechadas entre las cosas. Las funciones de la ironía - argumenta Ramos - no se limitan a una afirmación crítica del sinsentido del mundo sino que, además, permite dar cuenta de la complejidad de la realidad, subrayar la interdependencia de los contrarios e, incluso, cómo las oposiciones entre contrarios pueden diluirse para convertirse cada uno en lo otro. Ramos destaca con Brown algunas ironías decisivas para dar cuenta de los procesos de cambio social (la denominaciones son de Brown): "la ironía cósmica o de los acontecimientos, por la que lo que acontece se muestra contrario, a causa del destino o de los dioses, a lo esperado, y la ironía dramática o dialéctica, por la que el curso completo de los acontecimientos muestra de manera ineluctable cómo la búsqueda de algo da lugar a su contrario" 
saben condenados de antemano al fracaso y atrapados en un mundo reinado por la confusión y la anarquía en el que viven a la deriva (Frye, 1957: 192).

\section{Conclusiones}

Para Ricouer, la narración constituye una imitación o representación creadora de una experiencia temporal viva, conflictiva, discordante mediante la trama (1995: 80). Durante el proceso de distanciamiento del contexto social originario, las narraciones crean un tiempo que no es el tiempo del mundo sino el tiempo de la narración, dentro del cual se integran las diversas temporalidades de la experiencia: el tiempo de lo narrado, el tiempo del narrador y el tiempo del lector $^{20}$. El tiempo creado por la narración no tiene por qué ser responder al tiempo cronológico aunque en ocasiones lo haga, puede tratarse de un tiempo mítico, de un tiempo que transcurre un ritmo más rápido o más lento, de un tiempo dilatado o comprimido.

Por otra parte, esta estructura temporal de la narración va a inaugurar un nuevo tipo de relación de los sujetos con el pasado y el futuro. Por un lado, una relación con el pasado basada en la continua rectificación y corrección de las narraciones que uno cuenta y de los relatos transmitidos por una cultura específica (Ricouer, 1995: 998-1000, 1016). Por su parte, la relación con el futuro está mediada por las anticipaciones, previsiones, proyectos y planes. El tiempo narrado va a hacer visible la contingencia del pasado y del futuro.

De esta tensión permanente entre la delicada concordancia aportada por la narración y la abrumadora discordancia que procede de los acontecimientos imprevisibles en el contexto de la construcción de la trama, se deduce que la identidad narrativa no es una identidad estable sino que se hace y se deshace continuamente. $Y$ es en esta capacidad de recomposición narrativa donde reside la fortaleza (y la debilidad) del sujeto convertido simultáneamente en narrador y personaje de sus acciones. La identidad del personaje surge, pues, al mismo tiempo, y con las mismas dificultades, que la identidad/unidad de la historia narrada (Ricouer, 1996: 146-7). En consecuencia, somos la historia que somos capaces de contar sobre nuestra realidad. No obstante, los individuos no pueden contar cualquier historia. Como se decía más arriba, las formas narrativas disponibles en el acervo cultural del contexto social originario establecen los límites de las tramas narrativas y, en consecuencia, de la configuración de las identidades, lo que provoca que los individuos seleccionen y ordenen los acontecimientos vitales que articulan sus identidades de tal manera que puedan encajarse en las formas narrativas disponibles para poder ser inteligible ante los otros.

\section{Referencias bibliográficas}

ARENDT, Hannah. (2003). Entre el pasado y el futuro. Barcelona: Península. BAUDRILLARD, Jean (1978). Cultura y simulacro. Barcelona: Kairós.

BAUDRILLARD, Jean (1998). "The End of the Millenium or the Countdown". Theory, Culture and Society, 15 (1) 1-9. London: Sage. 
BAUMAN, Zygmunt (2003). "Del turista al peregrino o una breve historia de la identidad". Hall, S. y du Gay (eds.) (2003). Cuestiones de identidad cultural, Buenos Aires: Amorrortu.

BAUMAN, Zygmunt (2006). Modernidad líquida, México: FCE.

BECK, Ulrich y BECK-GERNSHEIM, Elisabeth (2003). La individualización. El individualismo institucionalizado y sus consecuencias sociales y políticas. Barcelona: Paidós.

FRYE, Northorp (1957). Anatomy of criticism. Princenton: University press, 1973.

GERGEN, Kenneth. (1996). Realidades y relaciones. Una aproximación a la construcción social, Barcelona: Paidós.

GIDDENS, Anthony (1995). La modernidad y la identidad del yo. Barcelona: Península.

HALL, Stuart (2003). “¿Quién necesita la identidad?”. HALL, Stuart. y DU GAY, Paul (eds.) (2003). Cuestiones de identidad cultural. Buenos Aires: Amorrortu. KOSELLECK, Reinhart. (1993). Futuros Pasados. Barcelona: Paidos.

LAHIRE, Bernard (2004). El hombre plural. Barcelona: Bellaterra.

LUHMANN, Niklas. (1992a). "El futuro no puede empezar: Estructuras temporales en la sociedad moderna". En RAMOS, Ramón (comp.). Tiempo y sociedad. Madrid: CIS.

LYOTARD, Jean Francois (1989). La condición postmoderna. Madrid: Ediciones Catedra,

PARDO, José Luis (2004). La regla del juego, Madrid, Galaxia-Gutemberg Círculo de lectores.

PADAVIC, Irene (2005). "Labouring under uncertainty: Identity Renegotiation among Contingent Workers". Symbolic Interaction, 28 (1), 111-134

RAMOS, Ramón (1993). "Una aproximación a las paradojas de la acción social". En LAMO DE ESPINOSA, Emilio. y RODRIGUEZ IBÁÑEZ, José Enrique (eds.). Problemas de teoría social contemporánea. Madrid: CIS.

RAMOS, Ramón (1995). "En los márgenes de la sociología histórica: una aproximación a la disputa entre la sociología y la historia". Política y Sociedad, 18, 29-44

RAMOS, Ramón (inédito). Poética de la no intencionalidad: la ironía y las tramas narrativas.

REVILLA, Juan Carlos y TOVAR, Francisco (2009). "La (re)producción

narrativa de la identidad laboral y sus condiciones de posibilidad". En CRESPO, Eduardo, PRIETO, Carlos y SERRANO, Amparo (eds.). Trabajo, subjetividad y ciudadanía. Paradojas del empleo en una sociedad en transformación. Madrid: UCM y CIS.

RICOEUR, Paul (1995). Tiempo y Narración. Madrid: Siglo XXI. RICOUER, Paul (1996). Sí mismo como otro. Madrid: Siglo XXI

SENNETT, Richard (2000). La corrosión del carácter. Madrid: Anagrama.

WAGNER, Peter (2001). Theorising Modernity. London: Sage

WESTENHOLZ, Anne (2006). "Identity Work and Meaning Arena". American Behavioral Scientist, 49 (7) 1015-1029

WHITE, Hayden (1992). Metahistoria: la imaginación histórica en la Europa del siglo XIX. México: Fondo de Cultura económica. 